A DISCUSSION oN 1

\section{CONTRIBUTION TO THE STUDY OF HEMIANOPSIA,}

\section{WITH SPECIAL REFERENCE TO ACQUIRED} COLOUR-BLINDNESS,

In the Section of Ophthalmology at the Annual Meeting of the British Medical Association held in Glasgow, August, 1888.

By GEORGE MACKAY, M.D., F.R.C.S.E., M.R.C.S., Assistant-Surgeon Eye Dispensary of Edinburgh, Ophthalmic Surgeon New Town Dispensary, Lecturer on Practical Ophthalmoscopy.

Mr. President and Gentlemen,-My purpose in addressing you to-day is to draw attention to the desirability of investigating cases of hemianopsia of all kinds with more thoroughness and precision than is usually shown in the published reports of such cases.

Starting, then, from a physiological standpoint, I shall first invite your attention to some preliminary remarks on the

Compound Nature of the Visual Sense.

For practical purposes, physiologists and ophthalmologists have for many years (at least on the Continent) regarded the sense of light as primarily consisting in three special perceptions, namely, the light-sense, form-sense, and colour-sense. In this country the practical utility and full significance of this differentiation has been more tardily recognised, but in two recent works by British ophthalmologists ${ }^{1}$ it has received due recognition and adoption. Though perhaps neither complete nor scientifically exact, this subdivision is undoubtedly of value, as suggesting a convenient method of estimating the state of the visual functions in health and disease.

The order in which these three kinds of perception have been mentioned expresses rightly their relative importance for useful vision since neither the second (the form-sense) nor the third (the colour-sense) are able to manifest themselves as existent if the first (the light-sense) be destroyed; and, again, the third may be markedly defective without failure in the other two becoming apparent, for example, in congenital colour-blindness. The precise nature of their mutual relation has not yet been ascertained, and it is, therefore, all the more desirable that in suitable cases of disordered vision, we should neglect no opportunity of estimating their condition. This at least is self-evident that, provided the musculature and refractive media of the eyes be normal, these three kinds of perception, when objectively evoked in the normal act of vision, are dependent on a healthy condition of the visual nervous apparatus, namely, the two retinæ, optic nerves, chiasmic crossing, optic tracts in their extra- and intra-cerebral course, and, finally, their central and cortical terminations.

When we endeavour to discriminate between them more nicely and allot each to its proper place of origin or seat in the visual nerve mechanism, our task becomes more difficult. In the present instance, I shall go no further than the assertion that it is the function of the retina, when stimulated by light vibrations, to initiate the nerve commotions on which these sensations are dependent; that it is the function of the optic nerves and tracts to conduct these commotions to the cerebrum; and that it is the function of the cortical substance of some part or the whole of the occipital lobe to bring them into the sphere of our conscious perception. It is more than probable that the basal ganglia with which the optic tracts are connected are not directly concerned in the production of visual sensations.

Lastly, with a view to investigating the condition of these sensations, it is important to remember that, since they may arise when one eye alone or both, or different parts of one or both, are exposed to objective stimulation, we must not be content with examining the central parts of the visual field of each eye separately, but must extend our inquiry to the peripheral parts also. As I shall have occasion to refer to the methods of investigation later on. I pass now to the consideration of that form of hemianopsi: which I have taken as the title of my paper.

1 Subjective Symptoms in Eye Diseases, by G. A. Berry, M.B. A Handbook of Diseases of the Eye, 2nd edition, 1888. By H. R. Swanzy, M.B.

[1454]
Hemranopsia of Central Origin.

It may now be said to be a well constituted fact in cerebral pathology that a lesion of an optic tract in its extra- or intracerebral portion or of one occipital lobe produces blindness of the visual half fields on the side opposite to the lesion (lateral homonymous hemianopsia), and according to the extent of the neural or cerebral injury the homonymous defect may be of the nature of a small scotoma at any part of the field, may be sectorlike, or involve the entire half of each visual field.

As regards its extent, then, the hemianopsia may be incomplete or complete. There is, however, another aspect in which we ought to regard these cases, namely, in relation to the degree of impairment of the visual power in the affected half fields. This seems to me to be deserving of much more attention than it has hitherto received, and is the text of my discourse to day.

In many cases of hemianopsia the lesion has been so destructive that not only the sense of colour and form, but even that of light, is lost, and the blindness in the affected areas may then be very properly termed absolute. But in some it has been found that the visual loss is partial, and it is said that such cases may be divided into two main groups:

1. Loss of colour-sense with perfect retention of form- and lightsenses.

2. Loss of colour- and form-sense, but light-sense intact in the affected areas.

Now of the first of the above groups there have been published by different observers a few cases under the title of hemiachromatopsia (Farbenhemianopsie or homonymous half-blindness for colours).

The characteristic features of these cases have been stated to be -retention of good central (direct) vision; good perception of colour, form, and light in one pair of half fields, while in the opposite half fields all colours appeared grey, but the senses of form and light were not only retained, but believed to be intact.

It has seemed reasonable to conclude that a lesion which can thus dissociate the visual functions, maiming one and sparing the others, has its seat in the cerebral cortical substance, or in other words the visual centres, and not in the optic tract or radiation, whose function is purely passive and conductive, unless, indeed, one accepts the theory that some nerve-fibres conduct only colour, others form, and the remainder light impressions, and that they form separate bundles in the optic tracts. And the above view has been further supported in the recorded cases by the fact that though there have been threatenings or previous attacks of hemiplegia or hemianæsthesia in one or two, the combined symptoms at the time of observation have not pointed to the base of the brain or internal capsule as the seat of the lesion, and that the only marked complaint has been of the visual disturbance.

Thus, to quote the words of Mr. Swanzy, of Dublin ${ }^{2}$ in reference to the first four cases recorded (see Analysis), these cases " go to prove that the centre for colour-perception is situated in the brain, and not in the eye or peripheral parts of the optic nerve, and moreover that in the brain it is a separate centre, distinct from that for the form-sense and for ordinary light-perception."

Dr. Gowers, in his recently-published work on Diseases of the Nervous System, p. 146, mentions all the recorded cases, and states that " the symptom (hemiachromatopsia) probably depends on disease of some part of the occipital lobe, and is proof of a separate centre for colour-vision." In making this assertion, however, he only follows the footsteps of Dr. Wilbrand, of Hamburg, who has taken up this opinion very strongly. ${ }^{3}$ Indeed, a consideration of these cases seems to have been the basis of his most ingenious theory of the constitution of the hemiopic visual centre, namely, that there is a special centre for colour, another for form, and a third for light. He believes these three centres may be disposed in the occipital cortex, either in a strata-like or in a superficial (side-by-side) arrangement; but whichever it be, their connection to one another is such that all the nerve filaments enter the light centre; those concerned in light impressions end here, those for form pass into the next centre accompanied by those for colour, but the latter terminate in the third (most distant or most superficial) centre.

This theory of a threefold centre, inasmuch as it has appeared to accord with clinical experience, seems to have been gaining ground. Mr. Swanzy gives it prominence in the second edition

2 Trans. Ophth. Soc., vol. iii, p. 188.

3 Ophthalmiatrische Beiträge zur Diagnostik der Gehirn-krankheiten, von Hermann Wilbrand, 1884. 


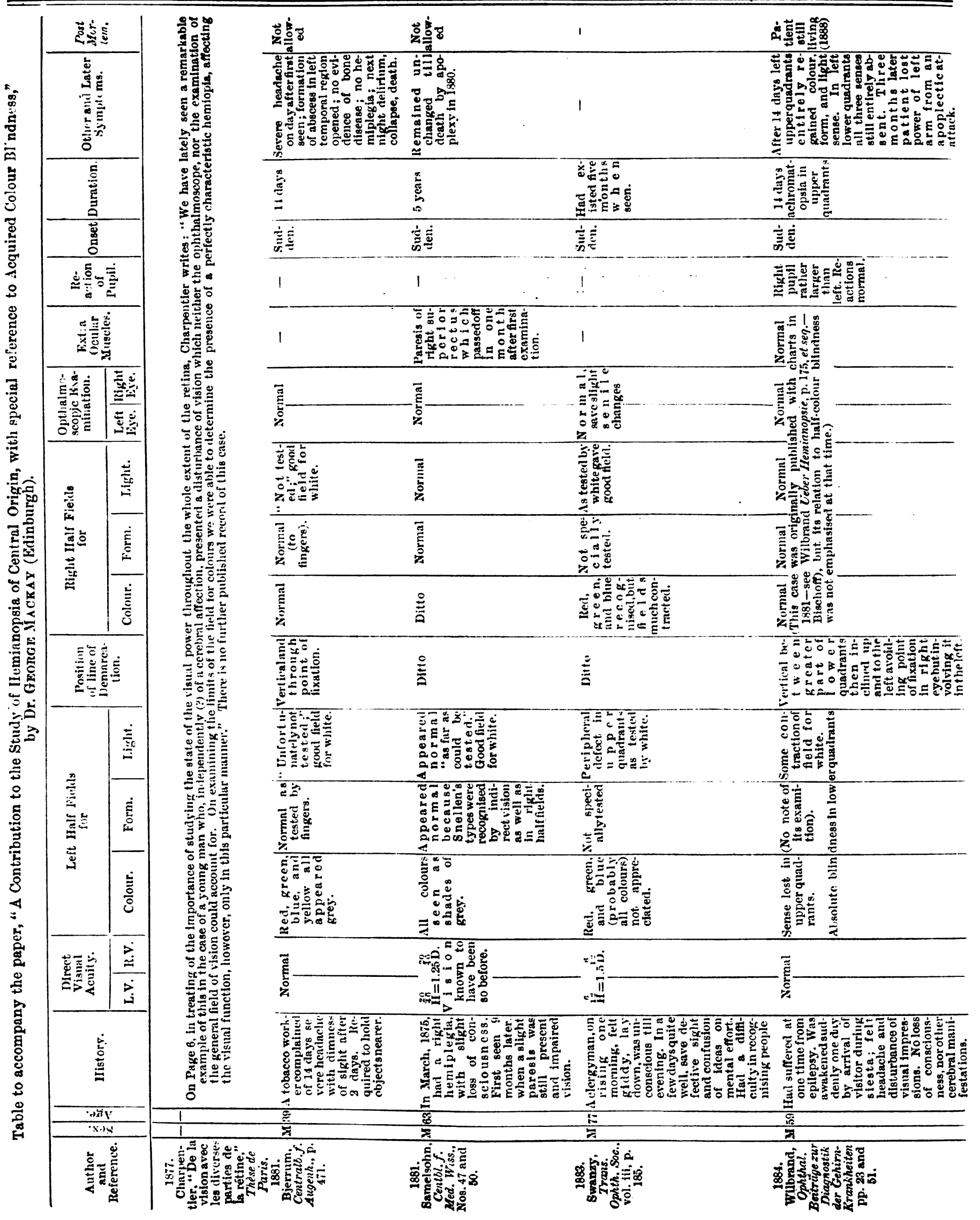


$=$ 10

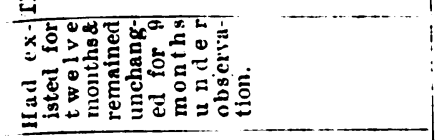

芦苛

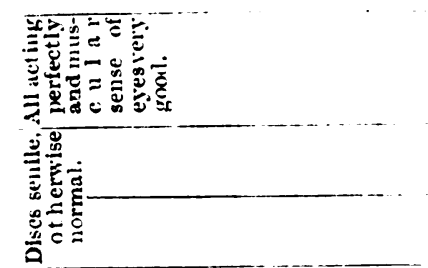

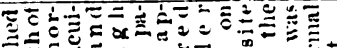

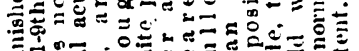

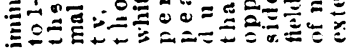

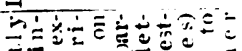

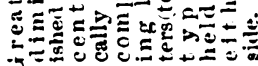

宁育

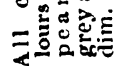

$\overline{\overline{\mathrm{E}}} \overline{\mathrm{E}}=$

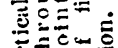

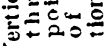

离
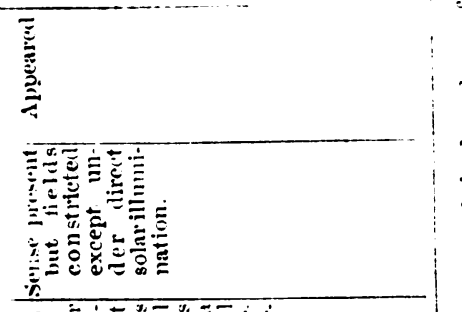

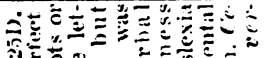

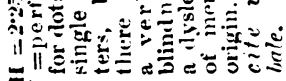

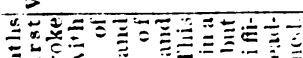

$=0 x$

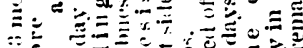

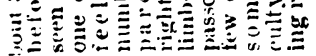

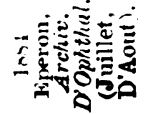

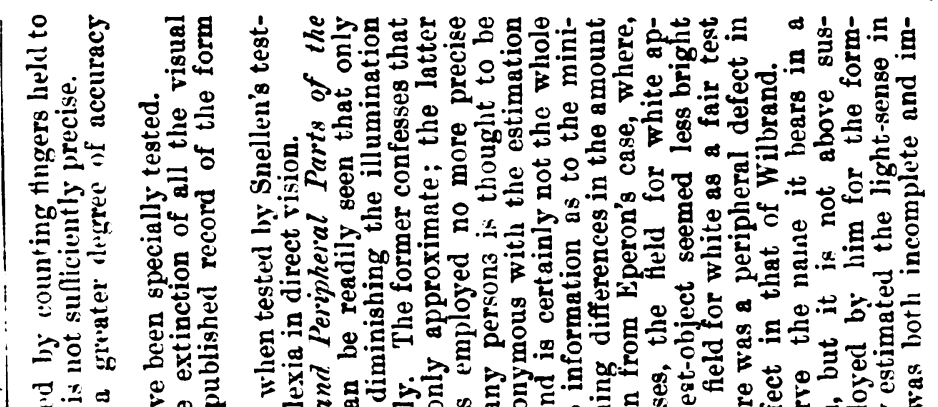

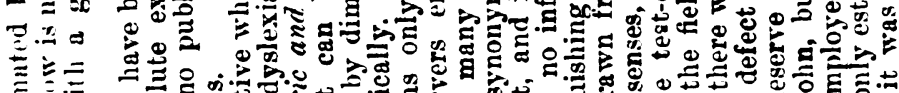

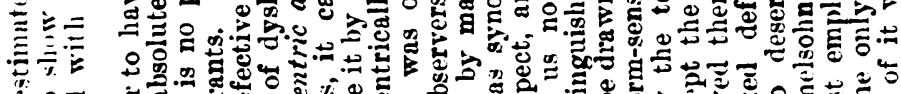

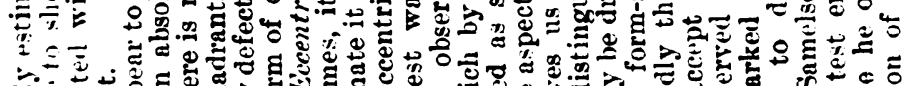

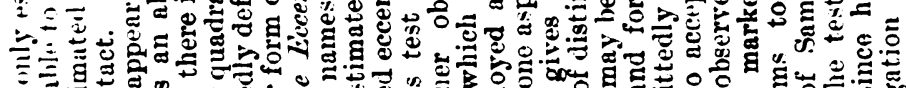
三.

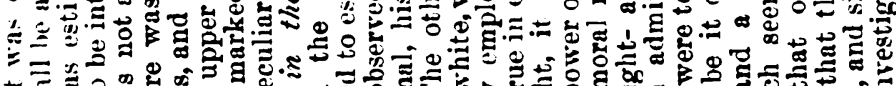

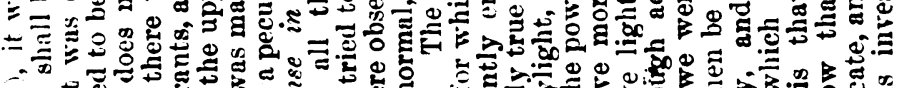

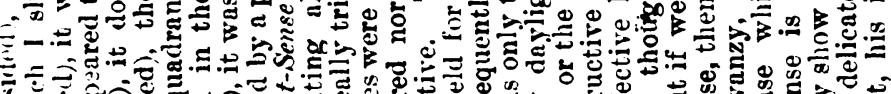

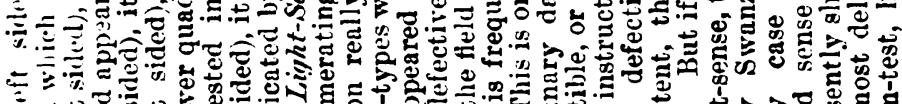

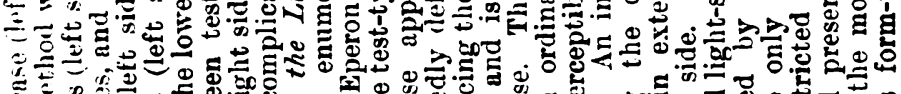

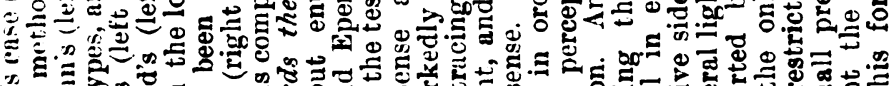
x.

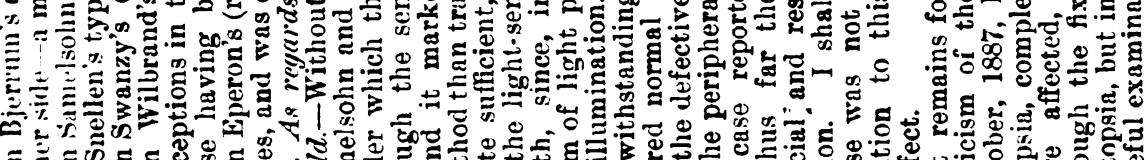

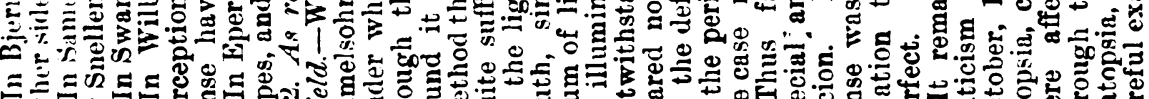

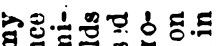

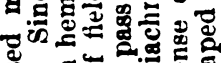

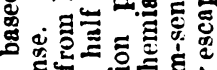

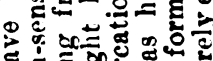

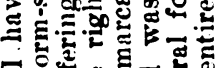

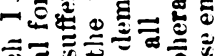

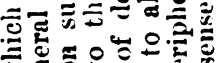

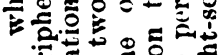

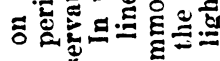

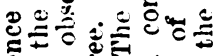

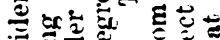

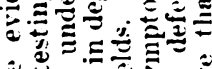
等

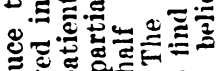
웅응

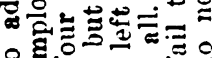

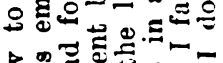

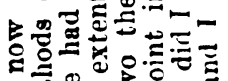

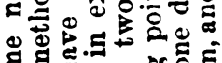

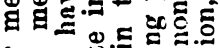
웡을

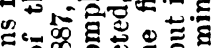

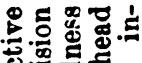

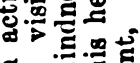
모을 论造豆 क्षे 훙 닐

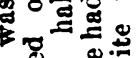

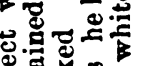

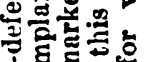
它是.

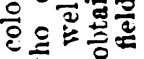
놀 要的 . 屯造 हू है 20.

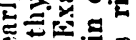

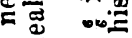
密

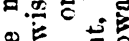

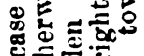

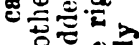

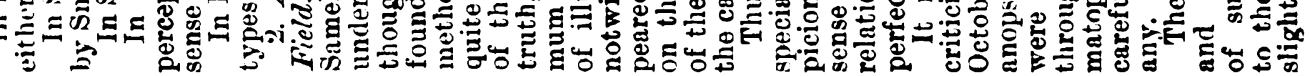




doed unusually large, and he appeared to cont fingers with

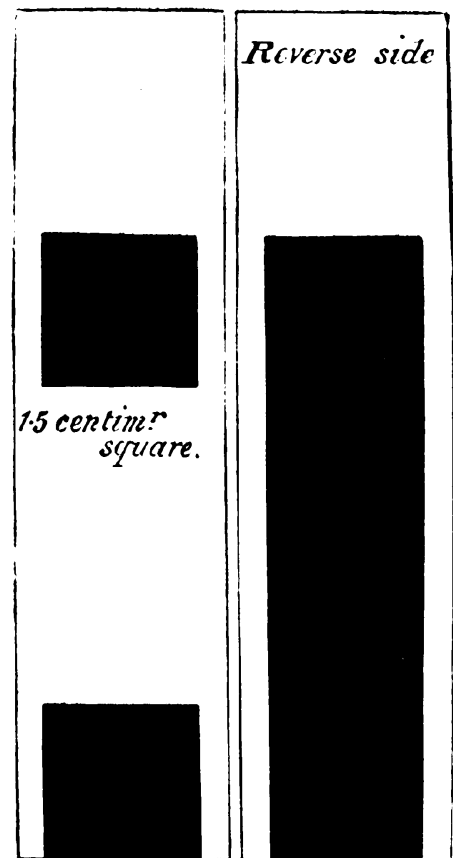
equal facility to either side. To estimate the form sense more accurately I enployed flrst (on the suggestion of Mr. Berry, but for whom this inquiry might not have been undertaken, and to whom I am under many ubligations for kindnesses recelved during its progress), a test object, such as I now exhibit, consisting of a piece of white cardboard 8.5 centimetres long by :2 centimètres broad. On one side it has two black squares, each 1.5 centimètre square, separated by a white space $t$ wice as long, and on the reverse a single black band equal to the combined extent of these. This card with its long axis vertical was brought along the arm of the perimeter, from the periphery of the horizontal meridian towards the centre of the field, first from one side and then from the other; each eye being of course separately examined and the card frequently reversed. The patient was asked to tell successively :-1. The moment at which the object was seen entering the field. 2 . Whether it appeared white or black. 3 . Whether there was one spot or more. 4. What was the shape of the spot or spots.

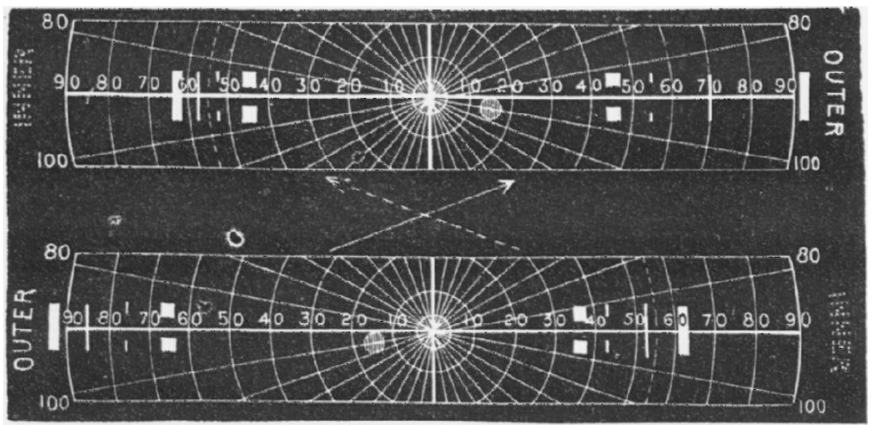

The First Diagram represents the linht Eye, the Second the Left Eye.

(The half fields must be contrasted in the manner suggrested by the arrows,

namely, right inner with left inner, and right outer with left outer.)

The first reply is indicated by the broad white band; it shows complete uniformity on the two sides. That the object was recognised further out than the usual limit of the risual field was due to its unusually large size. The second reply is marked by the narrow vertical line; the third by the two dots; the fourth by two small white squares. All these latter indicate a slight peripheral fuilure to the right, most marked as one might expect on contrasting the outer halves; the maximum difference amounting to $20^{\circ}$. The same kind of test was applied in another way. A 1.5 centimotre square of white paper was taken, as ordi-

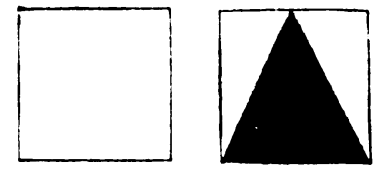

narily used for estimating the field for white. To one side of this n triangle of black paper was affixed so as partly to cover the wite surface. The patient was asked to say: 1. When he saw anything entering the fleld. 2. Whether it appeared white or ilack. 3. What was its shape.

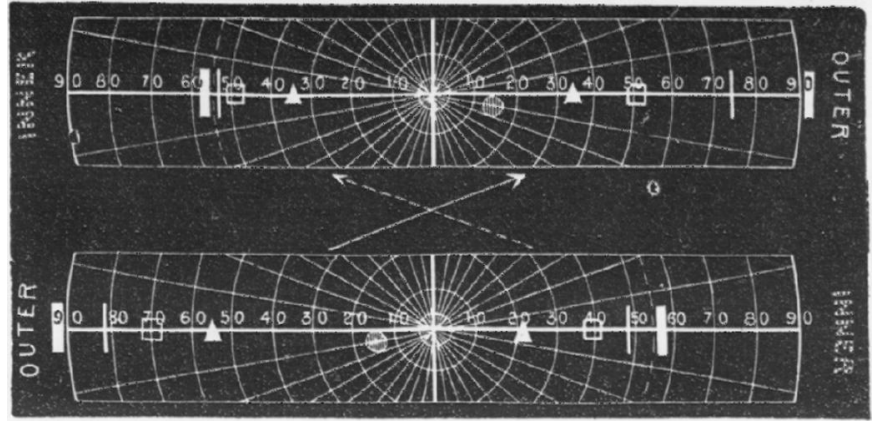

The First Jiagram represent t the Right bye, the Second the Left Eye.

The same indicators are employed for the first and second replies, as in the former chart and the half fields must be similarly contrasted. 'The square and triangle are markel at the positions where their shapes were respectively recognised.

In order to control the patient's replies, the test was further varied by substituting a black square for the black triangle, as above. Here, then, as in the former chart, there is proof of a slight peripheral loss of the form-sense, amounting ugain to a maximum of $20^{\circ}$ on the right side as compared with the left.

Enfortunately, in the course of a few days, and before I was aware that Snellen's types had been used by other observers, this patient's condition changed to almost absolute hemianopsia, so that I am unable to make any direct comparison in that respect. For the same reason I was also prevented in this case from investigating the state of the form-sense in other meridians than the horizontal; but I wish to take this opportunity of emphasising the importance of so doing, because 1 have found in other cases a marked difference in the condition of the upper and lower quadrants in the defective half fields. I also wish to lay stress on the preliminary questions about the recognition of black and white, since the replies to them will immediately revenl whether black and white test-objects are suitable. Thus, in one of my cases I found a marked defect for black and white, and therefore for all test-objects based on their use, associated with an apparently good power of recognising hand-morements in the periphery, and counting fingers or other equally large objects held excentrically.

To return from this digression. I nsk you to take notice that the first of these test-objects which I employed allowed of the form-sense being estimated on the sound side as far out as $45^{\circ}$ and $65^{\circ}$ recpectively in the inner and outer half fields; and from personal ohservation I am satisfied that either of them supplies a more delicate method for the periphery than the use of Snellen's test-types, or any such figure of complex form. For the recognition of a complex figure it is necessary that it should be of such a size that we not only appreciate it as a whole, but discern its separate parts. A smail test-type cannot be identified by a normal eye far from the point of direct fixation, and is, therefore, no proper test of the peripheral visual acuity. The smaller the type, the smaller the area tested. If a large test-type is taken, a larger surface of the retina is stimulated than by the test-objects shown to-day, and the test is less delicate.

I hope I shall not be thought too captious if 1 point out that the above remarks may be applied to Samelsohn's case with additional force. First, because it is questionable whether a patient whose direct visual acuity is below normal can have his peripheral form-sense equal to normal; and secondly, because this patient must have had a special difficulty, on account of his hypermetropia and presbyopia, in seeing objects, particularly those near at hand, even on the sound side. Two of my own cases afforded illustration of this difficulty, and showed further that the assistance to be derived from spectacles-as, indeed, is well known-is ordinarily limited to the central parts of the field of vision.

Lastly, one word about the light-sense. We have as yet no completely satisfactory method of investigating it in the periphery, so that any statement of its condition is apt to be imperfect and hazardous. Therefore, let us not theorise, but inquire.

Time will not permit of my giving further details of my own cases at present; but I shall take an early opportunity of recording them more fully. If the facts which I have exposed go to prove anything, it is surely that there is not yet any well constituted case where a hypothetical half-vision colour-centre has suffered alone, 
and other senses have been left "intact." It may be said that the apparently great preponderance of the colour-defect over that of the other senses is highly suggestive, or only explicable on the presumption that there are special centres; but that, owing to their close proximity, it is hardly possible for one to be injured without the others. While 1 admit the plausibility of that argument, it in no way alters my position in respect to the assertions made by the writers whom I have quoted, nor does it diminish the necessity for careful inquiry, especially as to whether the preponderance is real or apparent.

I shall not in conclusion be so illogical as to say that there are no special centres, for, in connection with the colour-sense in particular, I know that there are other recorded cases, congenital and acquired, which lend some probability to the theory of a special centre for colour. On other grounds I am not disposed to favour that theory, but it is beside my present purpose to discuss these. I have endeavoured to show that the imperfect investigation of one group of cases has led to deductions unwarranted by the facts before us, and that a fresh inquiry is necessary. I feel confident that cases of partial hemianopsia are far more frequent than is usually supposed, and not less certain that their more careful investigation is calculated to throw much light on the nature, relatinns, and localisation of the visual senses.

Mr. Hewerson said that he himself had hemianopia at times. The form from which he suffered was that suddenly in the right half of both retinæ he saw an appearance of an electrical discharge, which completely blotted out from that half of the field of vision all objects whatsoever; this was followed by severe pain on the left parietal region.-Dr. Bensos asked Mr. Hewetson if such appearances were not indicative of possible cerebral trouble? -Dr. Kart Grossmann thought that such cases were more like a scintillating 8cotoma. He had suffered from such attacks, and with him they were always followed by sickness and headache.Dr. MACKAY thought such cases functional; they should, however, receive as careful investigation as those due to gross lesion.

\section{GENERAL NEUROSES HAVING AN OPHTHALMIC ORIGIN.}

Read in the Section of Ophthalmology at the Annual Meeting of the British Medical Association held in Glasgow, August, 1888. BY H. BENDELACK IIEWETSON, M.R.C.S., Ophthalmic and Aural Surgeon, Leeds General Infirmary; late House-Surgeon
Leeds Public Dispensary.

Ir is now some years since I first observed symptoms, many and varied, occurring in neurotic persons who were also the subjects of uncorrected optically defective sight. In investigating more particularly the relationship between the various optic errors and sick headache, or simple headache, I was occasionally startled by the apparent direct relationship between the long uncorrected disorder (with all its immediate train of nerrous disorders) and general conditions of ill-health which seemed to be the direct outcome of a thus already demoralised nervous system. It is now well established that many cases of migraine or sick headache are directly attributable to the reflected irritation of the brain (and thence the gastric functions and heart's action) from some uncorrected optical state, chiefly on the side of hypermetropia, and always in a neurotic subject. It is also well proven that many of these cases are entirely relieved from their periodic attacks by the use of properly selected glasses; or, having passed an age when the activity of the accommodation ceases more or less, and the eye hecomes presbyoptic, the severity of the headache or migraine becomes greatly modified. It is further well lnown that $a$ patient, the subject of hypermetropia, is liable according to varying circumstances, such as extent of defect and use of the eyes, to more or less constant "head pains," not necessarily associated with very obviously defective vision, or aching eyes, but always peculiar in their position and character, and aggravated by close application of the sight. Although I have very fully published my observations some time ago on the relations between sick headache and optical defects, and utilised what was previously discovered as to the relation between headache (broadly defined as such) and bypermetropia, I had not felt my footing sufficiently to enable me to bring forward that which is now my desire to show, namely, that the neuroees growing and arising from congenital optical error are more subtle in their nature, more varied in their distribution, and more demoralising to the right evolution of the nervous system than I was at first led to suppose,

I particularly wish it to be clearly understood I do not think all sick headaches come from an optic defect, for it is well known that decayed teeth or central irritation of the ear or nose are frequently causes as well as other more general neuroses. But I have patients who have been martyrs to sick headache; who are also astigmatic, and in whom a complete cure has been effected by the use of cylindrical lenses, showing that when sick headache and its accompanying dyspepsia is due to reflected irritation in a neurotic subject, from the eyes to the stomach, complete immunity from attacks of this kind may be obtained ly glasses; and further, as I have observed, a very marked improrement in general cheerfulness and health. I may here remark that many persons who suffer from sick headache are astigmatic in an abnormal though slight degree, and it is only by straining their eyes by looking long and hard at some fine object, or exercising such feats of sight-seeing as "doing" the National Gallery and the Academy in one day. or severe microscopical study, reading, and the like, which will irritate the brain sufficiently to cause an attack. One patient says he always suffers from sick headache after watching a play ; another actually brings on headache, vertigo, and romiting by doing fine sewing; a third has sick headache only when reading for an examination; a fourth when she was at school, not since; but all proving to be ametropic, and completely cured by the systematic use of glasses constantly worn.

The most common forms of headache asscciated with that optical error known as hypermetropia are-either simply a heaviness or pain over the brows (this may or may not be combined with general headache), or very frequently a tender place on the top of the head, making it particularly painful to dress the hairsuch a pain as occurs after a lock of hair has been "slept on the wrong way," in common parlance; there is also frequently pain at the back of the head. All these pains may be present together, or they may exist singly, but they all occasionally occur in conjunction with serere neuralgia at the back of the neck. This I have frequently noticed, and where it occurred, whether associated with the other head pains or not, it, as well as they, soon disappeared with the systematic use of accurately adapted correcting glasses. This symptom of pain at the back of the head and neck is not one which has long been associated with optical defect, but I have now seen a sufficient number of cases to show without doubt that such may be safely regarded as one of the symptoms of (frequently latent) optical error, perfectly remediable by the use of glasses. and, when such, by glasees only.

Dr. Lauder Brunton wrote me that he has seen several cases of neuralgia of the back of the neck cured by glasses. It would not appear to need demonstration that with symptoms so severe and depressing to the general nervous system as are the rarious forms of headache-vertigo, which is associated with astigmatism vomiting; possibly, as I have noted, palpation, or neurotic dyspepsia between the attacks of migraine-other conditions should arise as a sequel in many constitutions. One which I particularly wish to draw attention to is insomnia. This particular symptom I observed in many cases the subjects of astigmatism. In one instance in particular, where the eres had given much trouble during the examination period of an Oxford man's life, it was particularly remarked to me that after the astigmatic trouble was corrected by suitable glasses, with an equal amcunt of work, the insomnia disappeared, and the whole physical and nerrous state of the gentleman improved greatly. One object of my paper will be to show what an important factor these optical errors are in, as it were, moulding during childhood and early life the nervous and constitutional state of the individual. As a proof of this I will quote two cases, both in ladies of education and refinement, which seem to give us some sort of clue to the possible effects on the constitution of persons who conscientiously struggle through a severe echolastic career with important optical errors entirely uncorrected.

The first case was that of a lady, aged :22, whom, some few years agn, I found to be the subject of compound hypermetropic astigmatism. Her health was not good, but she particularly complained of headache and general feelings of malaise. I corrected the astigmatism after very patient testing, since here great nervousnees made it a very trying process for myself as well as the patient. There were other symptoms, such as would be ordinarily covered by the convenient but too easily accesible 